\title{
The Nation-State, the Age/Gender System, and the Reconstitution of Erotic Desire in Nineteenth- Century Japan
}

\section{GREGORY M. PFLUGFELDER}

$\mathrm{P}$ UT SIMPLY, HAIR AND clothing make a difference. To phrase the matter another way, the presence of these material and visual forms, or alternatively their absence from the human body, embodies potent cultural meanings and has concrete effects in the social world. To be sure, more-hidden body parts may lurk below the surface that signal our membership in certain social categoriesgender, to give a prime example. In practical terms, however, when we see strangers walking toward us from a distance, we are in the habit of assuming they are a man or a woman not because we have observed their genitalia (it would be strange indeed if that were the case) but rather because we recognize and extract meaning from a more readily visible set of identity markers-primarily clothing-related (sartorial) and hair-related (tonsorial)—whose semiotic rules must be learned culturally and which vary across space and time.

The anthropological tradition reveals that the coding of social identity in hairstyle and clothing is a widespread principle of cultural organization. ${ }^{1}$ Nevertheless, in Japan during the early-modern Tokugawa era (1600-1868), tonsorial and sartorial codes went even further than in many other historical contexts as a means of regulating social difference. It is no exaggeration to say that for earlymodern Japanese such visible markers of identity constituted the primary signifier of belonging to a given social category. Typical examples may be found in the combination of long and short sword (daishō) that signaled one's status as a samurai male, or the hanging locks that, whether on a male or female body, conveyed the fact that one was still a child, or the fully shaved scalp that disclosed one's membership in the Buddhist clergy. Visual attributes like these were in some cases regulated by law, as with the twin swords, a privilege that Tokugawa authorities granted exclusively to samurai males; in other cases, tonsorial and sartorial norms were maintained by household custom, as with children’s locks, or institutional regulation, as with the clerical tonsure. Together, hairstyle and

Gregory M. Pflugfelder (gmp12@columbia.edu) is Associate Professor of Japanese History at Columbia University.

${ }^{1} \mathrm{~A}$ key theoretical work in this tradition is Hallpike (1969). 
clothing carried clues as to diverse aspects of social identity, including but not limited to gender, class, age, ethnicity, and religious status.

This essay probes the visual and material aspects of social signification in an attempt to rethink the history of sexuality in Japan during the transition from the Tokugawa to the Meiji period (1868-1912). In so doing, it parallels the trajectory of a number of other recent historians of sexuality, working in Foucault's wake, who, while acknowledging the fundamental role of discourse in structuring human knowledge and behavior, find themselves increasingly looking beyond the domain of language and textuality to consider some of the other cultural codes and material frameworks that shape the sexual realm. The following paragraphs can be read as an experiment in the use of visual methods for apprehending sexual meanings in the past. In the context of nineteenth-century Japan, it will be demonstrated, visual analysis offers a particularly valuable tool for adumbrating relationships between state and sexuality that do not reveal their outlines as clearly, if at all, through a linguistic medium.

The semiotic approach developed in this essay holds the potential, I believe, for clarifying a puzzle that scholars both of Japan and of sexuality have not yet satisfactorily explained, namely, why and how social attitudes toward male-male erotic desire shifted with such seeming rapidity from acceptance to repudiation in the decades following the 1868 reorganization of the nation's political structure known as the Meiji Restoration, which marked the emergence of the modern nation-state. More precisely, I would like to retrain our attention on the how, rather than the why, part of the question. Undoubtedly, the why question-in other words, identifying the larger motivating factors behind nineteenth-century changes in sexual ideology—remains a worthwhile task for historians to ponder. Yet without some understanding of the means by which ideology manifests itself in actual sexual behavior and object choices - that is to say, the how question-it demands a considerable leap of faith to imagine that sexual culture could have changed substantially in such a brief period of time. To articulate the crux of the conundrum a bit differently: if we assume, as many people do, that libido cannot be changed at will at the individual level, then how do we explain a shift in sexual norms across an entire society?

\section{The Way of Youths: Age/Gender Hierarchy as Fetish}

No less than in any other domain where people interact, the visible markers of social differentiation help to structure practices and desires in the domain of sexuality. In Tokugawa Japan, the salience of these codes finds vivid illustration in the "way of youths" $(s h u d \bar{o})$, a widely acknowledged set of cultural conventions that defined male-male sexual desire in positive terms, but only if the male object of pursuit fell into the category of "youth" or wakashu. The pursuer of the youth might also legitimately fall into the category of wakashu, but more 
typically he was imagined as a man-in other words, an adult male who had once held wakashu status but who had subsequently relinquished it. In principle, all males in Tokugawa Japan passed at one point in their lives through the wakashu life stage, which simply corresponded to the interval between childhood and manhood. ${ }^{2}$ Yet identity as a wakashu did not in and of itself require participation in any particular form of sexual relations. What it did, instead, was to place the individual within an age-defined subset of the larger male population that the shudo tradition regarded as exclusively worthy of esthetic appreciation and erotic pursuit by fellow males.

Age, however, is not an absolute quantity but rather a social category and can, accordingly, be reckoned in various ways. In modern societies, chronological age (age in years) and biological age (age as manifested in physiology) have come to serve as two of the most common modes of comprehending age. So wide is their currency that we tend to think of them as universal. Distinctions of age remain far more essentialized and underinterrogated in modern cultures than other forms of social hierarchy (gender, class, race, and so forth) both in our everyday life and in our scholarly thinking. Yet it is precisely those forms of discrimination-again, in the sense of making difference-generally regarded as natural and unproblematic that reveal the underlying structures of a given social order, as well as the limitations of what can be imagined, within that context, as "democracy."3 Far from existing primordially, all systems of age differentiation have a history. Although modern methods of age reckoning construct age difference out of factors (specifically, nationally regulated time and biomedically understood corporeality) that ostensibly lie beyond the scope of human intervention, they are no exception in their historicity.

In nineteenth- and twentieth-century Asia, the implementation of new structures of age hierarchy, and the displacement of older ones, formed an intrinsic if often overlooked part of the transition to modernity. In the case of Japan, the shift occurred largely in the late nineteenth century-the Meiji period-simultaneously with the emergence of the modern nation-state, which relied increasingly on centrally standardized norms to regulate the identities and behaviors of its citizens. Medical institutions, too, had an important part to play in redefining modern Japanese notions of age and particularly in naturalizing biological interpretations. Nevertheless, in keeping with the larger panel's theme, the focus of this essay rests on state authorities and on the impact that Meiji

\footnotetext{
${ }^{2}$ Further research on village society-in which, of course, the majority of Tokugawa Japan's population lived-is needed to test this generalization, which rests largely on print, and hence urban, sources. Nevertheless, at least as depicted in urban popular culture, the progression of age categories among males differed little between city and countryside.

${ }^{3}$ I am not here advocating that four-year-olds vote in national elections. I merely seek a more conscious recognition that even what passes for radical egalitarianism in modern political thinking routinely ejects from the equation certain forms of culturally constructed and naturalized difference.
} 
administrative policies made in reshaping practices of sexuality inherited from the Tokugawa period.

In Tokugawa Japan, neither chronological nor biological age had determined the point one entered the ranks of "youth" nor the time of one's exit. In fact, when reckoned in years, the temporal coordinates of "youth" status varied considerably - early-modern Japanese texts yield examples ranging anywhere from seven to thirty and beyond - and they might even differ significantly between individual members of the same household. ${ }^{4}$ Nor was inclusion in or exclusion from the wakashu category dependent on any specific physiological traits, as was the case, for example, with the appearance of facial hair that the Greeks of classical times equated with the arrival of manhood, and which biological science in the eighteenth- and nineteenth-century West codified as one of the body's "secondary sex characteristics. ${ }^{55}$ Instead, it was coiffure and clothing more than any other factor that labeled a particular individual as a youth, and hence as a legitimate object for the sexual desire of other males.

Aptly enough, the most common name for the rite of passage from youth into manhood in Tokugawa Japan explicitly evoked the change in socially appropriate attire that took place at this juncture: genbuku (today pronounced genpuku), an originally Chinese-derived term that referred from as early as the seventh century to the practice among aristocratic males of donning a prescribed form of headgear upon coming of age, a rite dubbed uikōburi ("first capping") in the native language. Among Tokugawa males of samurai or townsman status, the corresponding sartorial change, also part of a complex of cultural practices commonly referred to as genbuku, typically involved a modification in the cut of the kimono from one characterized by low-hanging sleeves (furisode) with open vents near the armpits to one with unvented sleeves that did not dangle so far from the arm. Not only did the change in costume come to function as a broad cultural signifier for the attainment of manhood, but the youthful garments that at this point were left behind also became eroticized and fetishized as part of the sexual objectification of the wakashu category. The image of swinging sleeves, for example, formed part of a standard poetic vocabulary that accompanied literary descriptions of the desirable wakashu, as well as finding prominent representation in woodblock depictions of that figure, including the one reproduced on this journal's cover. ${ }^{6}$

The journey from childhood to youth to manhood in Tokugawa Japan was further articulated through a series of hairstyle modifications. The process was

\footnotetext{
${ }^{4}$ It should be noted in connection with these figures that Tokugawa Japanese, like most East Asians before the modern era, counted age by the number of calendar years a person had lived in since birth, rather than the number of birthdays he or she had celebrated, as in the contemporary Western (as well as the present-day Japanese) system. Therefore, an individual aged "fifteen" in Tokugawa Japan might be anywhere from thirteen years and a day to exactly fourteen years old according to the Western tally.

${ }^{5}$ On the emergence of the biological model, see Laqueur (1990).

${ }^{6}$ For visual representations of the wakashu, see Hayakawa (1998) and Tanaka and Shirakura (2002).
} 
characterized by the shaving of an increasingly extensive area of the male scalp, accompanied by the binding of the hair at the back of the head into a forward-looping topknot. Children, whether male or female, did not wear this style of topknot; in fact, one of the most commonly used expressions for "child"-warawa, along with variants such as warabe-seems to have referred originally to the hanging locks that were conventional among that age group. ${ }^{7}$ When the boy progressed in age to wakashu status, he began to bind his hair in the prescribed topknot-in all likelihood, other household members initiated and assisted with the tonsorial change — and, in addition, a patch of hair at the top of the crown would henceforth regularly be shorn (nakazori) [see Figure 1(a)]. Together, these marks functioned as a signal of gender intensification as well as of age transition. Yet another modification of hairstyle among males often took place at some point before genbuku, when the natural hairline of the wakashu's forehead was partially indented at the temples to give it a more angular appearance, called "putting in corners [sumi or kado]" [see Figure 1(b)]. Finally, at the time of genbuku, the youth's forelocks were removed completely so that hair now grew freely only at the sides and the back of the head [see Figure 1(c)]. The distinctive hairstyle of the youth, and in particular the forelocks that swept upwards in front of the shaved patch of crown, was often regarded as the wakashu's most attractive-“sexiest," one might say-physical attribute. Indeed, Tokugawa writers sometimes used the term for forelocks (maegami) as a synonym for the youth himself. Once that conspicuous feature was removed, leaving the topknot the most prominent part of the coiffure, the youth was unquestionably a man in the eyes of early-modern Japanese society.

The esthetics and erotics of shudo thus focused on an appreciation of the youth's visible differences from the adult male. It is partly for this reason that the modern notion of "homosexuality" (in Japanese, dōseiai; cf. Ch: tongxinglian, Kor: tongsŏngae, Viet: đồng tính luyến ái), which emphasizes the sameness of biologically determined gender between sexual subject and sexual object, is ill-suited to describe shudo sensibilities, which presumed that a man and a youth were two distinct varieties of human being. Although the subject and object of shudo may both have belonged to the category of male in terms of genitalia, their differing roles in the erotic relationship hinged on an age asymmetry that was definitively established through hairstyle and clothing. ${ }^{8}$

\footnotetext{
${ }^{7}$ For simplicity's sake, I do not delve deeply here into children's hairstyles, some of which involved binding the hair in a special way and/or shearing certain portions (or even all) of the scalp. The key point is that children's hairstyles in Tokugawa Japan were visibly distinguishable from their wakashu counterparts. For discussions of Tokugawa childhood, see Mihashi (1992) and Ujiie (1994).

${ }^{8}$ According to shudo conventions, if a sexual relationship existed between the two parties, the wakashu (or else the younger of the two wakashu) played the insertee, rather than the inserter, role. For more on shudō norms, see Pflugfelder (1999), especially chapter 1.
} 
(a)

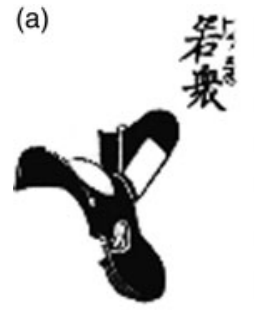

(b)

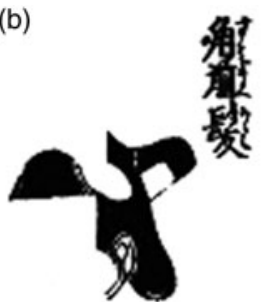

(c)

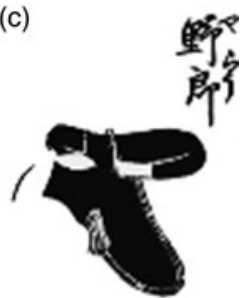

Figure 1. Male youth hairstyle transitions from wakashu to genbuku status.

The very term "way of youths" registers the fact that both gender and age played a crucial structuring role in shudo ${ }^{9}$ However, rather than seeing here an exceptional conjuncture of two discrete principles of social organization-age and gender - it may be more fruitful to consider these two dimensions of difference as being far more interlocked in cultural (and not simply sexual) practice than most people usually realize. Western discourses on gender accord considerable prominence to binaries such as man/woman or male/female, and therefore we tend to think of them as dichotomous. Yet even in the English vernacular, as in many of its European counterparts, we are accustomed to dividing the social world into "men, women, and children," a taxonomy that integrates considerations of age no less organically than those of gender. Likewise, popular texts and images of the Tokugawa period imagined the sexual economy of the "floating world" as composed of three rather than two distinct types of human agent: "men, women, and youths" (nyo-jaku-dan), to use one author's formula. ${ }^{10}$

Gayle Rubin's notion of the "sex/gender system" provides relevant food for thought here. In a classic essay, Rubin (1975) differentiated between sex as a physiological description and gender as a social construction, an analytical distinction that remains useful today. Rubin, an anthropologist, located the crucible of gender formation in the kinship system, the perpetuation of which over time has, at least until quite recently, depended on the exogamous exchange of reproductively capable bodies. As a feminist thinker, Rubin parsed social reproduction primarily in terms of male and female roles, yet it is not only gender that defines people's mode of incorporation into the reproductive economy. Age hierarchies, too, conventionally range people according to their (potential) roles in social reproduction, so that the distinction between child and adult holds at its core no less sexual a meaning than the male/female axis with which it interacts to produce such age/gender statuses as girl, boy, woman, and man-or, in the case of Tokugawa Japan, the post-child, pre-adult category of youth (wakashu).

\footnotetext{
${ }^{9}$ The Chinese-derived term nanshoku (Ch: nanse), or "male colors," which Tokugawa Japanese sometimes used synonymously with shudo, does not explicitly contain an age referent, but here, too, the object of pursuit was typically imagined as a youth.

${ }^{10}$ The phrase nyo-jaku-dan appears prominently in a 1700 work of popular fiction called An Amorous Stalk of Plume Grass. See Momo no Hayashi ([1700] 1985, 111).
} 
Not only a sex/gender system but also an age/gender system occupies a central place in societal and cultural organization. To retool one of Rubin's definitions, an age/gender system is a "set of arrangements by which the biological raw material of human aging is shaped by human, social intervention."11

Returning specifically to the age/gender system as it has evolved in Japan, what bears stressing for the sake of understanding nineteenth-century developments is the material plasticity of "youth" status. As we have seen, membership in the category was socially grounded in two distinctive aspects of physical appearance, namely, hairstyle and clothing. Significantly, both these attributes were greatly susceptible to human intervention. By comparison, youngness in modern Western societies, seen as based on time and physiology, is a quality over which people have little control. According to our modern understanding, maturation into adulthood, too, depends on chronological and biological factors, the latter often being culturally represented, in the case of the male body, by the appearance of hair on the face, a symbolic trope we have inherited from the Greeks. ${ }^{12}$ In Tokugawa Japan, it was not the appearance of new hair on the head, but rather the removal of existing follicles_-namely the shaving of the nakazori patch, followed by the shearing of the forelocks-that made a difference. The first of these acts of hair subtraction marked the entry of the male body into the realm of sexual objectification, while the second signaled its departure.

The plasticity of the category of wakashu, in turn, allowed various individuals and social constituencies to manipulate the visual and material traces of membership in it so as to include or exclude certain male bodies from the realm of eligibility or desirability as shudō objects. The fact that removing hair is physically easier than growing it, of course, facilitated the process. Tokugawa lawmakers, for example, when faced with unruliness among kabuki fans in the mid-seventeenth century, chose to target the visual dynamics of desire by decreeing that the wakashu actors over whom patrons were swooning could henceforth tread the stage only if they shaved off their forelocks, thus presumably dousing audience passions. ${ }^{13}$ Conversely, pleasure-industry entrepreneurs had an economic interest in maximally prolonging the erotic appeal of young male workers by having them sport the wakashu clothing and hairstyle long after most of their chronological-age cohort (to put the matter in modern terms) had abandoned them. ${ }^{14}$ And among ordinary households,

\footnotetext{
${ }^{11}$ The original quote, which refers to "sex and procreation" rather than "aging," may be found in Rubin $(1975,165)$.

${ }^{12}$ The word "puberty" (for which no exact synonym existed in Tokugawa Japan) reflects explicitly its classical Mediterranean heritage, being related to the Latin puber, meaning "downy," as in downy cheeks.

${ }^{13}$ For more on kabuki policy, see Shively (1955).

${ }^{14}$ The trope of the superannuated male actor-prostitute is a common motif of Tokugawa popular fiction. For one example, see Ihara ([1687] 1990, 267-71).
} 
parents might seek to protect a particularly attractive son from potentially bothersome sexual entanglements by carrying out genbuku on the early side. ${ }^{15}$

The Tokugawa-period association of male erotic objecthood with specific sartorial and tonsorial markers, and the susceptibility of those same cultural forms to modification through human agency, would have significant consequences for the viability of shudō practices and desires in the changing visual and material environment of the late nineteenth century.

\section{The Meij Reorganization of the Age/Gender System: Nationalizing Age and Gender Hierarchies}

In the years following the 1868 Meiji Restoration, the phrase "civilization and enlightenment" (bunmei kaika) echoed in the mouths of many Japanese. Both these terms, whether singly or in combination, offered a shorthand for the farranging agenda of social and cultural changes that contemporary government leaders and intellectuals espoused as appropriate for an imperially unified and internationally engaged "new Japan." Not least of the changes was a realignment and reconstitution of gender categories. Under the centralized Meiji nation-state, the class status (mibun) of one's household and its regional location on the checkerboard of military rule, both of which factors had been hereditary, no longer formed the primary basis of official identity, as had been the case under the more administratively fragmented and class-segmented Tokugawa sociopolitical order. Instead, gender moved to the foreground in determining the individual's civic and societal obligations. More precisely, it was the genital distinction between male and female that came to outweigh other modes of defining gender, including the erotic triangle of "women, youths, and men" that Tokugawa popular culture had validated for more than two centuries. Under the Meiji polity, legal gender simply equaled physiological sex. Regarding anatomy as civic destiny, Meiji lawmakers discriminated between male and female in such areas as inheritance, political rights, military duties, educational choices, and professional opportunities. Medical authorities played an important role in maintaining the official dichotomy of sex, testifying in court, for example, as to the "true" sex of apparent hermaphrodites (han'in'yō). ${ }^{16}$

Like gender, age, too, continued to provide a dominant ordering principle within Meiji society, even as its nature was redefined. In determining the relationship of the individual to the polity, Japanese officials had long distinguished between adults and pre-adults in various ways, although the age criteria they had applied often differed by region and by class. With Meiji political centralization, legal definitions of age became standardized at the level of the

\footnotetext{
${ }^{15}$ The travails of parents with attractive sons are a recurring theme in Ujiie (1995).

${ }^{16}$ Modern Japanese notions of hermaphrodism are discussed in Algoso (2006).
} 
nation-state. Over the course of the Meiji period, lawgivers in Tokyo fixed national ages of sexual consent (twelve before 1907; thirteen afterwards), of military conscription (for males, twenty), of political enfranchisement (for propertied males, twenty-five), and so forth, now officially counted in years of life (mannenrei; cf. Ch: zhousui, Kor: man nai, Viet: tuổi tây), along European lines, rather than calendrical years (kazoedoshi; cf. Ch: xusui, Kor: Hanguk nai, Viet: tuổi $m u)$. Chronological age also integrated individuals into the apparatus of the nation-state through the normalizing and synchronizing institutions of the education system, which were segregated by sex above the primary level. Henceforth, a young person's age could be communicated as meaningfully by referring to his or her grade in school as by his or her age in years. Simultaneously, the Meiji era witnessed the institutional consolidation of biological science, which defined the aging process as a sequence of morphological and functional changes that were internal, rather than external, to the body.

Under the rigidified age/gender system of Meiji Japan, the triangular sexual economy upon which the Tokugawa "way of youths" was premised swiftly collapsed. Scholars of Japanese history have sought to explain the demise of shudo in various ways, many of them invoking vague generalizations such as "modernization" and "Westernization." ${ }^{17}$ What I wish to advocate is a more concrete approach to the question, using a perspective that is both material and semiotic. Hair and clothing, I have been at pains to stress, make a difference. They help create and maintain social distinctions of gender as well as of age. As we have seen, it was precisely these distinctions upon which the esthetics of the "way of youths" had been based. What would happen to such an eroto-esthetic code if the visible markers that had regulated its system of meaning were physically erased?

Something like that very scenario occurred over the first decades of the Meiji period. Like their Tokugawa predecessors, early Meiji officials readily turned to sartorial and tonsorial means to pursue political ends. Sartorial policy was an important part, for example, of post-Restoration efforts to dismantle the hereditary status hierarchy of "four estates" (shimin) by which Tokugawa rulers had attempted to freeze the class order. The fledgling Meiji government revoked longstanding sumptuary regulations that outlawed dressing above one's social station, and, in 1876, it ordered members of the former samurai estate to desist from walking about with the twin swords, a symbol of authority that had once been that class's exclusive prerogative. The regulation of class might simultaneously implicate the regulation of gender, as in the case of samurai swords, which connoted not simply warrior status but more particularly warrior masculinity. Authorities' concern with gendered appearance manifested itself explicitly in a Tokyo misdemeanor code of 1873, which prohibited males from attiring themselves as females, and females as males. The framers of the code made legal

\footnotetext{
${ }^{17}$ For a "modernization" approach to changing sexual ideology, see, for example, Watanabe (1980); see also Watanabe and Iwata ([1987] 1989, 121-33).
} 
exception only for actors on the stage and for the conventionally male-worn skirttrousers (hakama) that an emerging social type, the schoolgirl, had adopted only recently (Pflugfelder 1999, 151-52). The costume of both the emperor and his empress, paramount symbols of the nation and of gendered adulthood, also received considerable attention from officials and underwent significant changes over the early Meiji decades.

Hair, too, continued to be a matter of official interest. As in the case of clothing, tonsorial reforms implemented changing ideologies of gender and age as much as they did those of class. In the realm of male grooming, official disfavor centered early in the Meiji period on the hairstyle colloquially known as chomage (or chonmage), which laid the bound-up topknot of the adult male flat along the crest of the shaved pate. English-language accounts sometimes misleadingly describe the hairstyle in question as a "samurai topknot," yet adult males of most ranks in secular society during the Tokugawa period had assumed the general outlines of that coiffure. To replace the outmoded chōmage, early Meiji advocates of "civilization and enlightenment" prescribed a European-style midlength haircut (zangiri) for all lay males, regardless of their age. Indeed, in some localities, police authorities resorted to shearing off the topknots of the recalcitrant by force. ${ }^{18}$ Meanwhile, females who affected the same unbound and cropped coiffure-as some intrepid young women began doing shortly after the Restoration-faced stiff fines under misdemeanor codes promulgated in 1873 for Tokyo, the newly colonized island of Hokkaido, and other parts of the archipelago. ${ }^{19}$ In effect, the officially endorsed hairstyle erased the immediately visible signs of age (and class) hierarchy among males, even as it reinforced the gender dichotomy of male and female.

Through tonsorial policy and the "civilizing" of vernacular custom, youthscolloquially, "forelocks" - as a social category simply ceased to exist. Under the visual codes that would prevail for the remainder of the Meiji period, shudo esthetics, at least in their conventional form, were no longer recognizable, and the "way of youths" as it had been conceived in Tokugawa times increasingly became an object of ridicule, condemnation, or simply ignorance. Furthermore, male-male sexual practices faced new constraints in Meiji criminal law, particularly in cases involving legally defined minors. ${ }^{20}$ Nevertheless, as the history of "sodomy" law in Europe and America likewise shows, the criminalization of specific sexual acts (for example, anal intercourse [keikan] in the case of the Kaitei ritsurei, Japan's penal code from 1873 to 1881) has at best a limited effectiveness in reshaping human libido. In fact, actual keikan prosecutions seem to have been exceedingly rare during the Kaitei ritsurei era, whereas

\footnotetext{
${ }^{18}$ For more on Meiji policing of hairstyle, see O'Brien (2008).

${ }^{19}$ On female haircutting, see Murakami (1969-72, 2:287-93).

${ }^{20}$ Meiji legal discourse is analyzed in Pflugfelder (1999, 146-92), where, however, Kaitei ritsurei is mistakenly transcribed as Kaitei ritsuryō.
} 
tonsorial/sartorial policies and customs impacted the visual and material environment for nearly everybody in the Japanese archipelago. Given these circumstances, any attempt to understand sexual ideology in the Meiji period must take into account not only the documentary evidence that historians have traditionally relied on, but also the visual and material context that surrounded those written words and that drew them into relation with the lived experience of erotic desire.

To summarize, several decades before the medical notion of "same-sex love" (dōseiai) would achieve popular currency in Japan — a phenomenon largely of the twentieth century-Meiji "civilizers" had already begun to groom the bodies of the nation's subjects for the strict sex dichotomy upon which its logic depended. ${ }^{21}$ Even as national authorities enforced genitally defined gender as one of the prime determinants of social identity-overriding class, religious status, and other factors - they began also to standardize age categories in ways more amenable to central control and biomedical definition. The age/gender statuses that came to weigh importantly in state regulation of individual behavior depended less on outward appearance and localized custom than on factors over which individuals or households had little power of intervention. Chronological age integrated bodies into national institutions in ways that were easily trackable and uniform across the entire population, while biological age invested the body itself with an internalized developmental trajectory. By the twentieth century, a new sequence of age/gender categories_yōji (infant), shōnen (boy), seinen (adolescent male), seijin (adult of either sex), chünen (middle-aged person), and röjin (elderly person), to give one version-had come to define the normative male life-course, their boundaries being variously defined by legal, physiological, and psychological criteria. ${ }^{22}$

It is worth mentioning, finally, that male-male eroticism did not disappear in Japan during the late nineteenth century; instead, it wore new clothes. Well after the Meiji Restoration, popular images of the male erotic object commonly configured him in terms of his age as well as his gender. In some cases, the "beautiful boy" (bishōnen) of the Meiji imagination wore the contemporary guise of a student; other authors and artists pictured him as a sprightly naval cadet. $^{23}$ Both icons of young male eroticism sported an identifying uniform and, if not a unique hairstyle, at least distinctive headgear in the form of a school or military cap. Tellingly, even as both figures prolonged a tradition of

\footnotetext{
${ }^{21}$ On the rise of the "same-sex love" (dōseiai) construct, see Pflugfelder (1999), especially chapter 5; see also Pflugfelder (2005).

${ }^{22}$ Although this essay focuses on male-bodied age/gender categories, an analogous, though not necessarily symmetric, restructuring of female identities unfolded over the same period. One fascinating example is the emergence of the category of shojo (girl) from around the turn of the twentieth century, on which see Suzuki (2009), especially part 1.

${ }^{23}$ On the figure of the "beautiful boy" in Meiji popular discourse, and especially the schoolboy, see Pflugfelder (1999, 212-34).
} 
social categorization and erotic fetishization by appearance, they testified to the growing subsumption of age and gender hierarchies into the institutional framework of the nation-state.

\section{List of References}

Algoso, Teresa A. 2006. "Thoughts on Hermaphrodism: Miyatake Gaikotsu and the Convergence of the Sexes in Taishō Japan." Journal of Asian Studies 65(3):555-73. Hallpike, C. R. 1969. "Social Hair," Man, n.s., 4(2):256-64.

Hayakawa Monta. 1998. Ukiyoe shunga to nanshoku [Erotic ukiyo-e and male-male eros]. Tokyo: Kawade shobō shinsha.

Ihara SaIKaku. [1687] 1990. The Great Mirror of Male Love. Translated by Paul Gordon Schalow. Stanford, Calif.: Stanford University Press.

Laqueur, Thomas. 1990. Making Sex: Body and Gender from the Greeks to Freud. Cambridge, Mass.: Harvard University Press.

O'Brien, Suzanne G. 2008. "Splitting Hairs: History and the Politics of Everyday Life in Nineteenth-Century Japan." Journal of Asian Studies 67(4):1309-39.

Minashi Osamu. 1992. "Konchikushō" kō: Edo no shinseishi [Thoughts on "konchikushō": A history of Edo mentalities]. Tokyo: Nihon editā sukūru.

Momo no HaYashi Shiseki. [1700] 1985. Kōshoku hitomoto susuki [An amorous stalk of plume grass], ed. Suisei Shoanjin. Koten bunko, no. 468. Tokyo: Koten bunko.

Murakami Nobuhiкo. 1969-72. Meiji joseishi [Meiji women’s history]. Tokyo: Rironsha.

Pflugfelder, Gregory M. 1999. Cartographies of Desire: Male-Male Sexuality in Japanese Discourse, 1600-1950. Berkeley: University of California Press.

2005. 'S' Is for Sister: Schoolgirl Intimacy and 'Same-Sex Love' in Early Twentieth-Century Japan." In Gendering Modern Japanese History, ed. Barbara Molony and Kathleen Uno, 133-90. Cambridge, Mass.: Harvard University Press.

Rubin, Gayle. 1975. "The Traffic in Women: Notes on the 'Political Economy' of Sex." In Toward an Anthropology of Women, ed. Rayna Reiter, 157-210. New York: Monthly Review Press.

Shively, Donald H. 1955. "Bakufu Versus Kabuki." Harvard Journal of Asiatic Studies 18(3/4): 326-55.

Suzuкi, Мicнiко. 2009. Becoming Modern Women: Love and Female Identity in Prewar Japanese Literature and Culture. Stanford, Calif.: Stanford University Press.

TANAKA Yūko and Shirakura Yoshiniko. 2002. Edo onna no iro to koi: Wakashu-gonomi [Edo women in love and lust: A taste for youths]. Tokyo: Kawade shobō shinsha.

UjIIE Мıкіто. 1994. Edo no shōnen [Edo boys]. Tokyo: Heibonsha.

—. 1995. Bushidō to erosu [Bushido and eros], Kōdansha gendai shinsho, no. 1239. Tokyo: Kōdansha.

Watanabe Tsuneo. 1980. "Kindai, dansei, dōseiai tabū [Modernity, the male, and the homosexual taboo]," pt. 1 of "Bunmei oyobi tōsaku no gainen [Civilization and the concept of inversion]," Kōchi daigaku gakujutsu kenkȳu hōkoku: Jinbun kagaku [Research reports of Kōchi University: Humanities] 29:27-45.

Watanabe, Tsuneo, and Jun'ichi Iwata. [1987] 1989. The Love of the Samurai: A Thousand Years of Japanese Homosexuality. Translated by D. R. Roberts. London: GMP. 